\title{
Modeling of Carbon Dioxide Fixation Rate by Micro Algae Using Hybrid Artificial Intelligence and Fuzzy Logic Methods and Optimization by Genetic Algorithm
}

Omkar Singh Kushwaha ( $\square$ kushwaha.iitmadras@gmail.com )

Indian Institute of Technology Madras

Haripriyan Uthayakumar

Anna University Chennai

Karthigaiselvan Kumaresan

Anna University Chennai

\section{Research Article}

Keywords: Adaptive Neuro-Fuzzy inference system, Genetic algorithm, $\mathrm{CO} 2$ fixation rate and Root Mean Square Error, Industrial scale-up, Carbon capture

Posted Date: September 13th, 2021

DOI: https://doi.org/10.21203/rs.3.rs-774165/v1

License: (c) (i) This work is licensed under a Creative Commons Attribution 4.0 International License.

Read Full License 
1 Modeling of carbon dioxide fixation rate by micro algae using hybrid Artificial

2 Intelligence and Fuzzy Logic methods and optimization by Genetic Algorithm

3 Omkar Singh Kushwaha ${ }^{11^{*}}$, Haripriyan Uthayakumar ${ }^{2 ~}$, Karthigaiselvan Kumaresan ${ }^{2}$

4

$5 \quad{ }^{1}$ Department of Chemical Engineering, Indian Institute of Technology, Madras, Tamilnadu, India

$6 \quad{ }^{2}$ Department of Chemical Engineering, Anna University, Chennai, Tamilnadu, India

$7 \quad *$ Corresponding Author E-mail: kushwaha.iitmadras@gmail.com

$8 \quad{ }^{\mathrm{T}}$ Equal first author contribution

\section{Abstract}

11 In this study we are reporting a prediction model for the estimation of carbon dioxide $\left(\mathrm{CO}_{2}\right)$

12 fixation based on the Adaptive Neuro-Fuzzy Inference System (ANFIS) and Genetic Algorithm

13 (GA) hybrid approach. The experimental parameters such as temperature and $\mathrm{pH}$ conditions of the 14 micro-algae-based carbon dioxide uptake process were taken as the input variables and the $15 \mathrm{CO}_{2}$ fixation rate was taken as the output variable. The optimization of ANFIS parameters and 16 formation of the model structure were performed by genetic algorithm (GA) algorithm in order to 17 achieve optimum prediction capability and industrial applicability. The best-fitting model was 18 figured out using statistical analysis parameters such as RMSE, $\mathrm{R}^{2}$ and AARD. According to the 19 analysis, GA-ANFIS model depicted a superior prediction capability over ANFIS optimized 20 model. The Root Mean Square Error (RMSE), coefficient of determination $\left(\mathrm{R}^{2}\right)$ and AARD for 21 GA-ANFIS were determined as $0.000431,0.97865$ and 0.044354 in the training phase and $220.00056,0.98457$ and 0.032156 in the testing phase, respectively for the GA-ANFIS Model. As a 23 result, it can be concluded that the proposed GA-ANFIS model is an efficient technique having 24 very high potential to accurately calculate $\mathrm{CO}_{2}$ fixation rate and the exploration of the industrial 25 scale-up process for commercial activities.

26 Keywords: Adaptive Neuro-Fuzzy inference system, Genetic algorithm, $\mathrm{CO}_{2}$ fixation rate and 27 Root Mean Square Error, Industrial scale-up, Carbon capture 


\section{Introduction}

It is evident that the rising in the level of gas emissions caused higher global temperatures which have led to the increase in frequency and the scale of the natural disasters (Xu et al. 2021; Appiah et al. 2021). These disasters and calamities are testing their extremes and have deeply impacted humans, animals and the plants. Human activities can be mostly attributable to the increase in greenhouse gases since the scaled industrial production leading to the industrial revolution (1880) (De Vries 1994). The greenhouse gas emissions which account to about 375 billion tonnes of carbon that have been emitted by humans into the atmosphere as carbon dioxide $\left(\mathrm{CO}_{2}\right)$, roughly estimated as 1374 gigatons, and the emission climbed to a recorded 37.1 gigatons in the year 2018 with very alarming future projections (Kahia and Jebli 2021; De Vries 1994). Significant reasons for such scaled emission involve the combustion of traditional fuels such as fossil fuels producing a large amount of $\mathrm{CO}_{2}$, which is responsible for climate changes and global warming. Statistically, the combined land and ocean temperature have increased at an average of $0.07^{\circ} \mathrm{C}\left(0.13^{\circ} \mathrm{F}\right)$ per decade since 1880. Scientific progresses to reduce the impact of emissions of carbon dioxide are undergoing in the broad fields of biotechnology (Ghosh and Kiran 2017), nanotechnology (Moniz 2010; Aiyer et al. 2016; Kushwaha et al. 2015; Meena et al. 2019) and renewable energy (Panwar et al. 2011). The promising results are obtained from solar cell technology (Brabec et al. 2001; Singh and Kushwaha 2013), fuel cell technology (Barbir 2012; Kushwaha et al. 2013; Kushwaha et al. 2014) and the wind energy (Burton 2011). Accounting to this, Carbon Capture and Storage (CCS) becomes an area of significant global interest and concern for the researchers. CCS is the most common method for $\mathrm{CO}_{2}$ management (Dods et al. 2021). CCS technology rose as the novel and effective carbon capture technology to achieve environmental benefits with harmful $\mathrm{CO}_{2}$ emissions to the atmosphere in the limited land area and energy benefits from derived algal biomass (Boot-Handford et al. 2014; Gibbins and Hannah 2008).

The Microalgae growing system might be a potential environmentally friendly technique for efficiently converting inorganic $\mathrm{CO}_{2}$ into biomass through photosynthesis, which can then be utilized to produce high-density biofuels and high-value medicinal components. Microalgae cultivation system offers several advantages such as high photosynthetic efficiency and growth rate, allowing it to be harvested in a short period of time; low-quality water, can be used for growth thus eliminating the need for extra nutrients; using non-fertile land not suited for agriculture; and 
microalgae having high tolerance towards $\mathrm{SO}_{\mathrm{x}}$ and $\mathrm{NO}_{\mathrm{x}}$ in flue gases thus $\mathrm{CO}_{2}$ demand might be met by using flue gas (Sayre and Richard 2010; Jonker et al 2013). The Figure 1 depicts the $\mathrm{CO}_{2}$ fixation using Micro-algal based process.

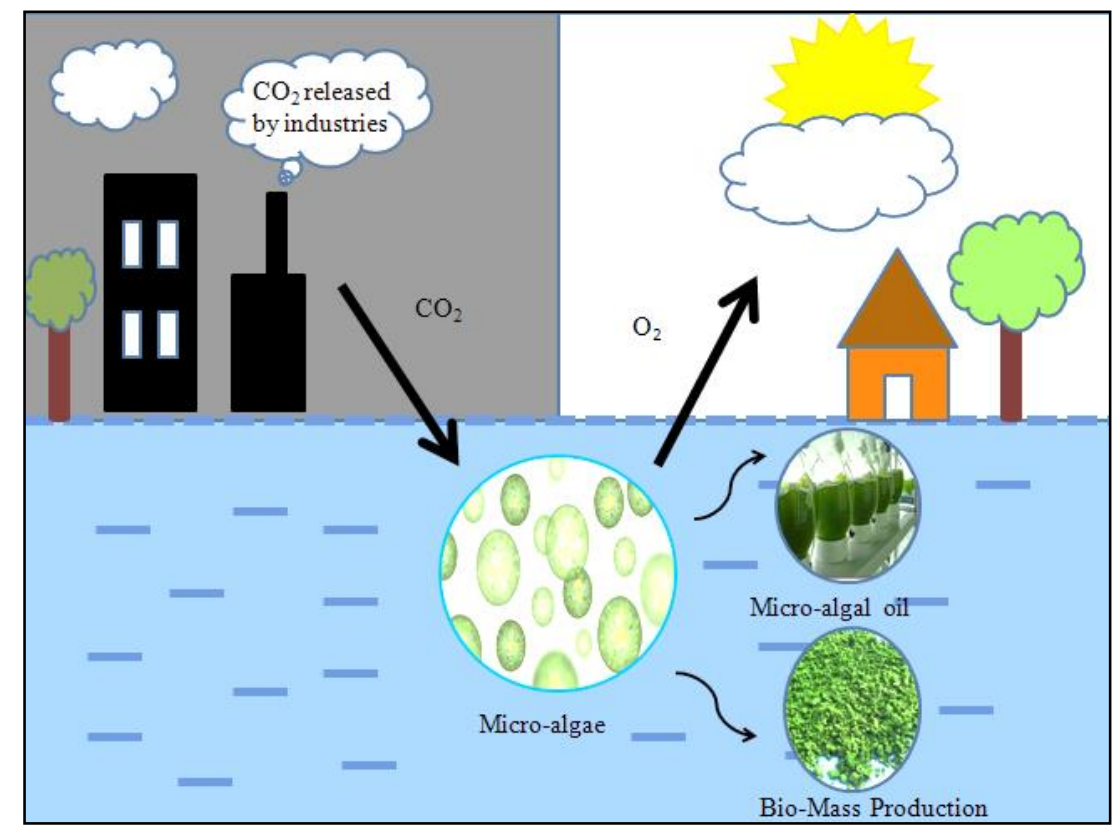

Fig. 1 A representative diagram showing carbon dioxide fixation using Micro-algae-based process

Artificial Neural Networks (ANNs) and Fuzzy Logic (FL) have been immensely used in many upcoming engineering and technological sectors (Jang 1993; Buragohain \& Mahanta 2008). ANN which is the branch of Artificial Intelligence (AI), function in a similar way to the human brain using historical data (Jang 1993; Buragohain \& Mahanta 2008). Figure 2 depicts the overview of the application of AI to solve Industrial Problems. They have the potentiality of learning from the datasets using the parallel connected nodes called neurons, which process inputs with respect to their adaptable weights usually in an iterative manner for approximation. (Buragohain \& Mahanta 2008) 


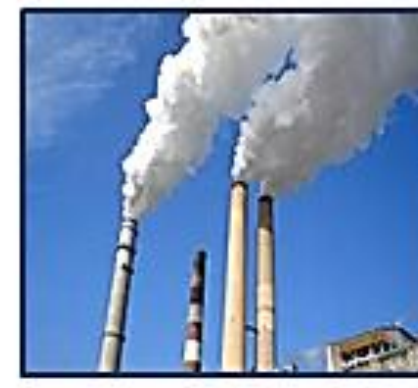

Input Data

(From Industries)

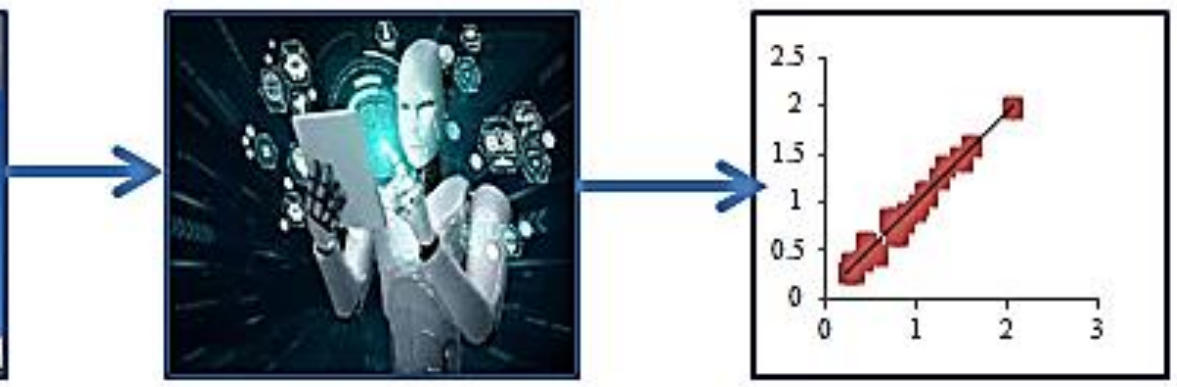

Computational Modeling (Artificial Intelligence)

\section{Prediction Analysis}

Fig. 2 An overview diagram of application of AI to solve Industrial Problems

Fuzzy logic is employed to manoeuvre the fundamental idea of partial truth, where the truth value may differ between completely true and completely false. Takagi and Sugeno improvised the Fuzzy Logic with a novel rule-based modeling technique (Rezakazemi et al. 2017; Singh et al. 2012). Acquiring the mathematical models was very intricate and sluggish in time consumption due to the complex process of designing the operating point and linearization. Fuzzy Logic permits one to generate a model for a system using human intelligence along with IF- THEN rules. On the other hand, ANN deals only with datasets rather than the linguistic expressions. Thus, the above inadequacy may be improved by combining both ANN and Fuzzy logic (Zhou et al. 2019; Singh et al. 2012).

This paper uses Adaptive Neuro Fuzzy Inference System (ANFIS) that eliminates the basic problems in ANN using the learning ability of fuzzy system design for automatic if-then rule generation and parameter optimization. The combination of ANN and Fuzzy system is called the Neuro fuzzy system (Zhou et al. 2019; Alarifi et al. 2019). ANFIS is one of the best hybrids of neural and fuzzy system, has better smoothness than ANN. Regardless of the fact that ANFIS can handle complicated engineering problems, it has a number of drawbacks, including a sluggish convergence rate, a low learning rate, and the possibility of being caught in a local extreme. An evolutionary algorithm combined with ANFIS was utilized to tackle these problems and improve network reliability by avoiding local minima and achieving global convergence quickly and 
correctly. Many optimization algorithms (OA), such as the genetic algorithm (GA), may be used to change the weight and bias of ANNs to improve their performance and lower the total mean squared error (Alarifi et al. 2019).

The concept of natural selection and hereditary behavior based genetic algorithms (GAs) are nowadays predominantly employed for the optimization than the other optimization techniques. The potentiality of the binary digit control system also causes the genetic algorithms distinctive from the rest other methodologies (Vaefi et al. 2015). Ergo there is an extreme necessity to construct such a model that can establish perfect connection between the output and the input factors. The GA integrated hybrid approach such as GA-ANFIS is propounded in this analysis, to scrutinize the impact of process variables on the $\mathrm{CO}_{2}$ fixation rate (Yang et al. 2020; Sarkheyli et al. 2015). The GA integrated hybrid approach is suitable to develop a better inter-connection between the process parameters and the response values by improvising the performance level of ANFIS model. In this work, the GA-ANFIS is used to optimize the micro-algae-based carbon capture process by varying the cultivating conditions ( $\mathrm{pH}$ and temperature) to obtain the bestdesired product and the most beneficial outcome $\left(\mathrm{CO}_{2}\right.$ fixation rate) (Vaefi et al. 2015; Yang et al. 2020).

\section{Materials and Methods}

\subsection{Dataset}

The principal focus of this study is to forecast Micro-algae selectivity based on the analysis results which can be acquired effortlessly, instantly and without needing exorbitant and sophisticated equipment. Thus, in this study, the components of analysis, temperature and $\mathrm{pH}$ are used as input parameters to obtain $\mathrm{CO}_{2}$ fixation rate as an output. To ensure that the proposed model has a wide range of validity, a data set containing $\mathrm{CO}_{2}$ with different characteristics was created by reviewing the literature (Jacob-Lopes et al. 2009; Murakami and Ikenouchi 1997; Yun et al. 1997; Scragg et al. 2002; Stephenson et al. 2010; Sakai et al. 1995; Chiu et al. 2011; Zhao et al. 2019; Huntley and Redalje 2007; de Morais and Costa 2007b; Gomez-Villa et al. 2005). Repeated samples were extracted from this data set and a simplified data set containing 27 samples was obtained. The 
temperature of samples was ranged from approximately $19{ }^{\circ} \mathrm{C}$ to $40{ }^{\circ} \mathrm{C}$ by weight. Similarly, the $\mathrm{pH}$ was found between 5.5 to 9.4. The output $\mathrm{CO}_{2}$ fixation rate was 0.280 to 2.04. In the present study only 27 datasets have been used so as to study the behavior of ANFIS and GA-ANFIS models on training, and testing a smaller number of datasets.

\subsection{ANFIS (Adaptive Network based Fuzzy Inference System)}

Adaptive neuro-fuzzy inference system is the combination of quick-witted techniques of neural network and fuzzy inference system. ANFIS is a unique methodology which is employed especially in the modelling of the non-linear functions. The modeling was performed to develop a relation between the independent and dependent variables. The advantage of using these soft computing methods is to develop a black box model without the need of mathematical models (Najafi et al. 2018a; Khashei-Siuki et al. 2015). The fuzzy system alone was unable to acquire the precise outcome because it couldn't alter the membership functions automatically. The amalgamation of both (ANN and Fuzzy) was capable of generating the precise value at any circumstances. ANFIS is used to formulate a heuristic pattern between the input-output based on the initial given fuzzy system and available input-output data pairs by employing learning methodologies (Yang et al. 2020; Najafi et al. 2018a). The most pre-dominantly employed fuzzy inference system (FIS) which are used in diverse applications are the Mamdani inference system and Sugeno inference system (Najafi et al. 2018a). Further, in the present study MATLAB R2020a software package was used to develop the models, and the modelling was performed in two stages: Training and Testing. In this work, $70 \%$ of the dataset is employed to train models and the remains, $30 \%$ is used for testing the models. The training stage is a vital step in the formation of networks. After developing the target network, the selected testing data is then applied to the network in order to obtain the results of the testing stage (Najafi et al. 2018a; Yilmaz et al. 2011). It is very important to go for the pertinent sample for training and testing towards the decrease of prediction error. Figure 3 represents the basic ANFIS model structure using MATLAB R2020a. 


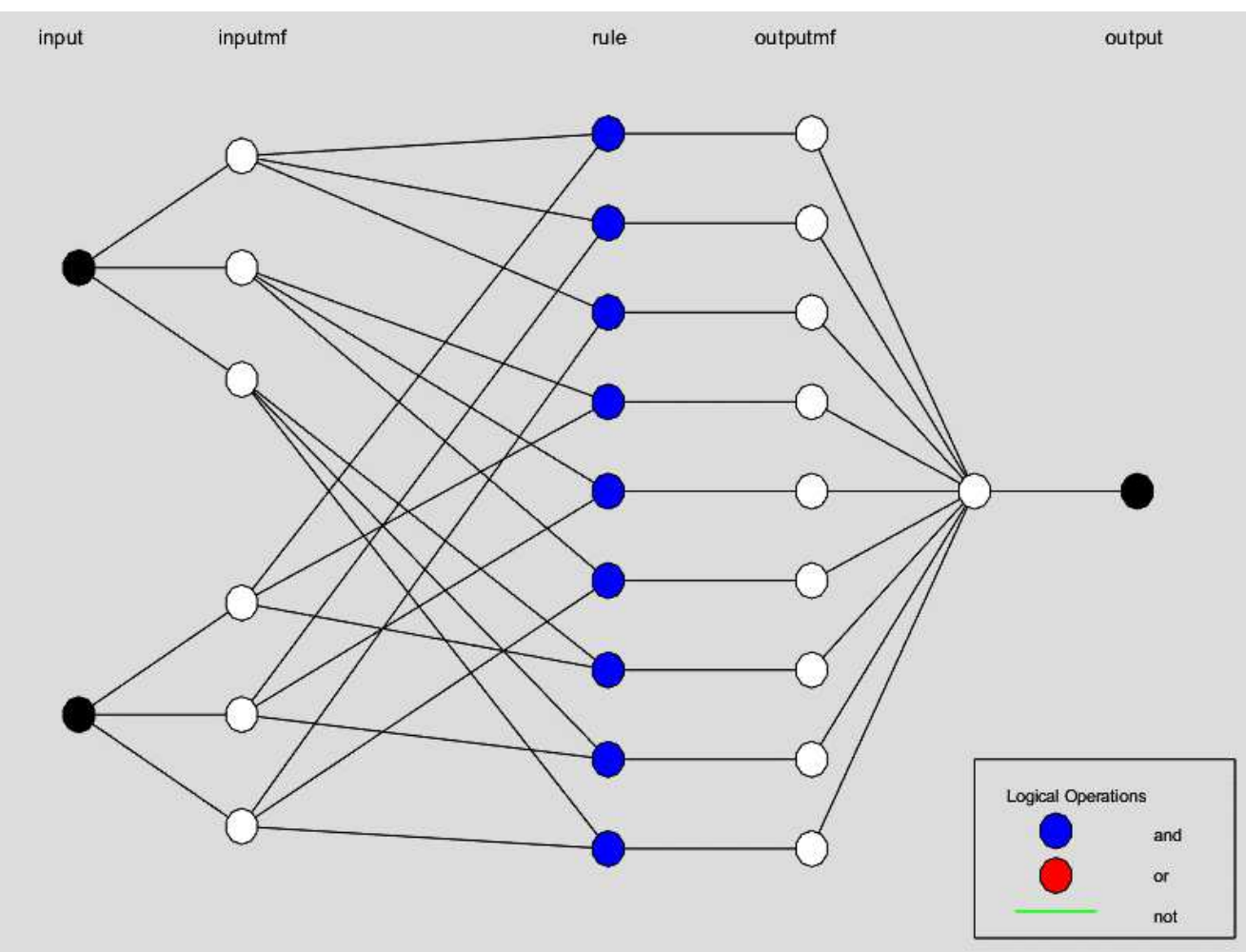

Fig. 3 A representative outlay of the basic ANFIS Architecture

\subsection{Modeling using ANFIS}

The two most commonly employed fuzzy inference systems (FI) which are used for various application are Mamdani inference system and Sugeno inference system (Rezaeianzadeh et al. 157 2014). In the present work ANFIS is constructed using Sugeno fuzzy model (Najafi et al. 2018b). 158 The representation of rules for Sugeno fuzzy inference system is given below in the Figure 4.

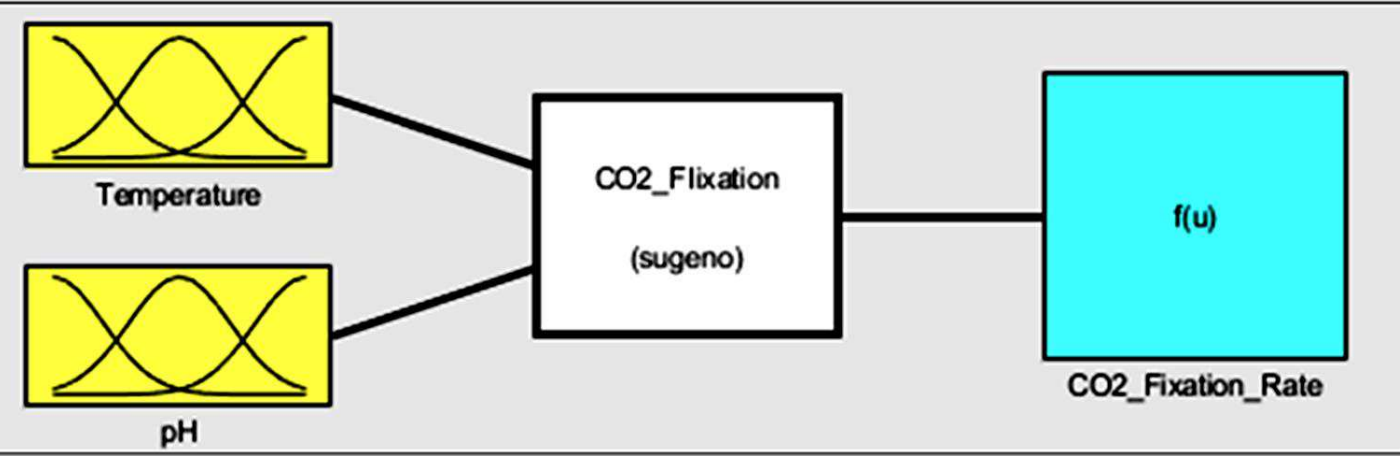

161 Fig. 4 A representative overview of the Sugeno fuzzy model. 
162 Rule 1: If $x$ is $A_{1}$ and $y$ is $B_{1}$, then $f_{1}=p_{1} x+q_{1} y+r_{1}$

163 Rule 2: If $x$ is $A_{2}$ and $y$ is $B_{2}$, then $f_{2}=p_{2} x+q_{2} y+r_{2}$

164 Where, $x$ and $y$ are the two inputs. A and $B$ are the membership function. $p$, $q$, and $r$ linear 165 parameter. 1,2, represent the number of rules.

166

167

168

The architecture of ANFIS comprises of five different layers. Each layer of the network accommodates several nodes described by the node function (Yaseen et al. 2017). The overview and further details of the multilayered ANFIS architecture can be observed in Figure 5.

\section{$170 \quad$ Layer 1}

171 This layer also known as fuzzification layer. In this layer the nodes are squares with a 172 Membership function associated with each one of them.

$173 \quad \mathrm{O}_{\mathrm{i}}{ }^{1}=\mu_{\mathrm{Ai}}(\mathrm{x})$

174 Where, $\mathrm{x}$ serves as an input to the particular node, $\mathrm{A}_{\mathrm{i}}$ being the linguistic label, $\mathrm{O}_{\mathrm{i}}{ }^{1}$ is the 175 output of the first layer and $\mu_{A_{i}(x)}$ is the membership function. The membership used in this 176 study is Triangular membership function (trimf) The further details regarding triangular 177 membership function for the input variables are given in Figure 6.

178

179

$$
f(x ; a, b, c)=\left\{\begin{array}{cl}
0, \quad x \leq a \\
\frac{x-a}{b-a}, & a \leq x \leq b \\
\frac{c-x}{c-b}, & b \leq x \leq c \\
0, & c \leq x
\end{array}\right\}
$$




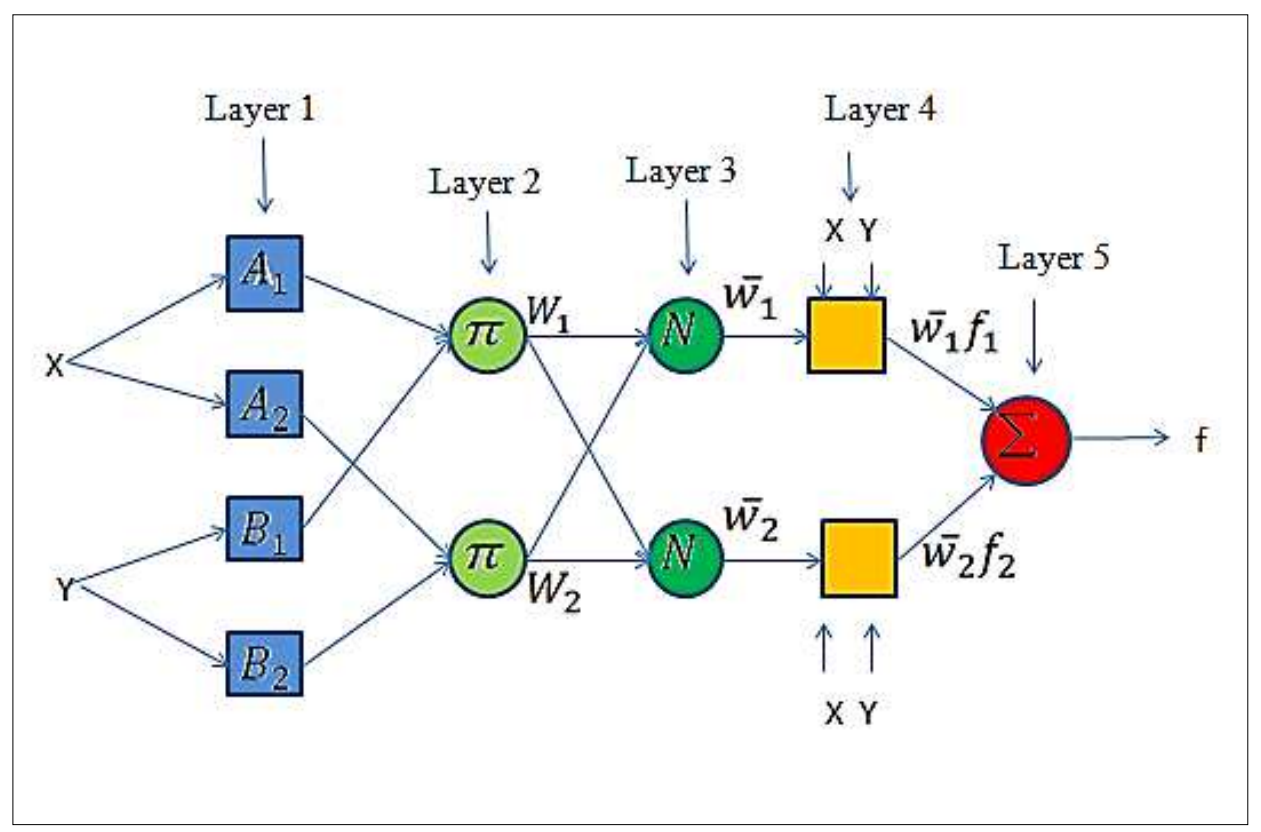

182 Fig. 5 A representative overview of the ANFIS Architecture.

$184 \quad$ Layer 2

185 Nodes of this layer execute the function of multiplying the inputs and passing out the product.

186 The output of various nodes depicts the strong firing of the rule.

$187 w_{i=} \mu_{A_{i}}(x) \times \mu_{B_{i}}(y), \quad i=1,2$

\section{$188 \quad$ Layer 3}

189 Nodes of this layer execute the purpose of calculating the ratio of the $\mathrm{i}^{\text {th }}$ rule's firing strength to 190 the sum of all rule's firing strength:

$191 \quad W_{i}=\frac{w_{i}}{w_{1}+w_{2}}, \quad i=1,2$

\section{$192 \quad$ Layer 4}

193 Nodes of this layer are adaptive in nature and execute the overall output:

$194 O_{i}^{4}=W_{i} f_{i}=W_{i}\left(p_{i} x+q_{i} y+r_{i}\right)$ 


\section{Layer 5}

196 This single node is a circular node with the symbol $\Sigma$ (sigma) that is employed to calculate the 197 overall summation of all the incoming signals.

$$
O_{1}^{5}=\text { overall output }=\sum_{i} w_{i} f_{i}=\frac{\sum_{i} w_{i} f_{i}}{\sum_{i} w_{i}}
$$

ANFIS employs the hybrid-learning algorithm, which comprises of the amalgamation of "gradient descent" and "least squares" methods to upgrade the model parameters (Yaseen et al. 2017; Kaveh et al. 2018)
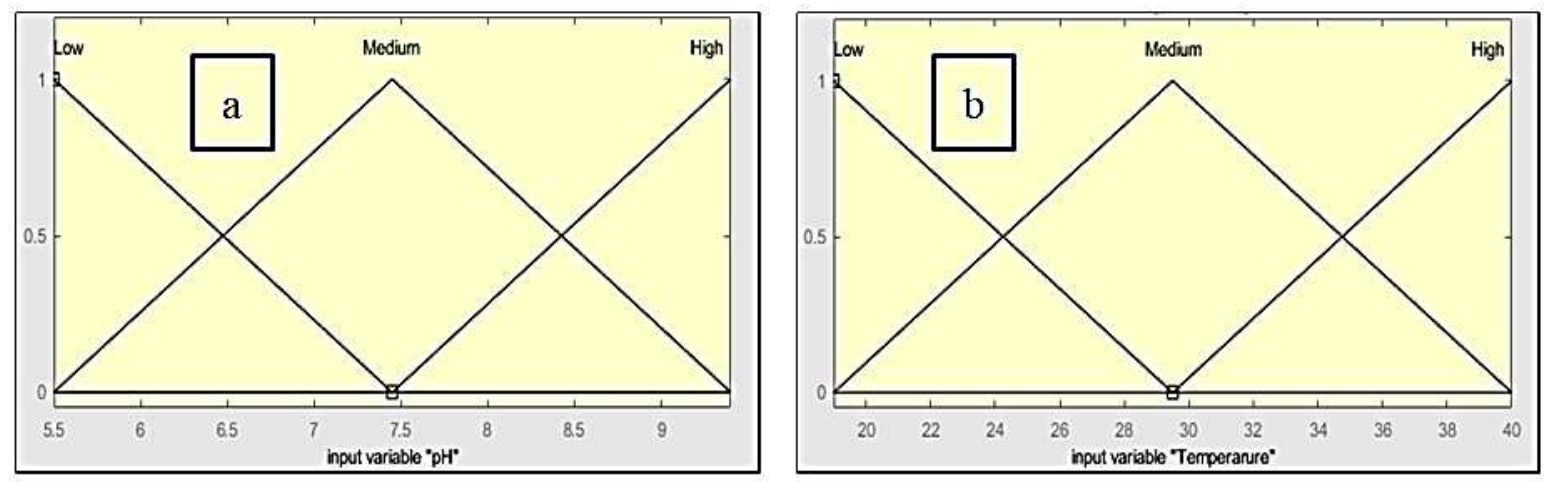

203

Fig. 6 Triangular membership function for the input variables (a) $\mathrm{pH}$ and (b) Temperature.

\subsection{Genetic Algorithm (GA)}

207 Genetic Algorithm (GA) is an evolutionary heuristic search algorithm which reckon on natural 208 selection and genetic science based on Charles Darwin's theory of Natural evolution. This 209 furnishes an arbitrary search that is employed to decipher optimization problems (Shahlaei et al. 210 2012, Maulik et al. 2000). In nature, rivalry between individuals for insufficient resources always

211 leads to the emergence of the strongest individuals who dominate the weakest. The GA generally

212 initializes by generating an initial population with an assemblage of possible solutions. Each 213 population has a chromosome with the same length as the total number of process variables (Houck 
214

et al. 1995; Maulik et al. 2000). The objective function fitness value is considered when assessing these chromosomes. Selection, Crossover, and Mutation processes are predominantly employed to create new chromosomes termed off-spring. The chromosome with the elevated fitness value has the best prospect of being chosen (Mathew 2012). In the present study the computation is accomplished when the fitness function and the chromosomes achieve the point of convergence, at which the optimum process parameter value for maximum $\mathrm{CO}_{2}$ fixation rate is attained (Shahlaei et al. 2012; Kaveh et al. 2018).

\subsection{GA-ANFIS hybrid approach}

GA-ANFIS is a hybrid approach for handling non-linear datasets where adaptive neuro-fuzzy inference (ANFIS) executes the process of training the dataset and eventually performs optimization using GA. ANFIS is a hybrid approach that uses the advantages of both neural networks' best learning skills and fuzzy systems' inference capabilities to accomplish a desired execution (Houck et al. 1995; Moayedi et al. 2019). The main objective of the fuzzy controller is to accomplish proper execution in the presence of fluctuations (Vafaei et al. 2015). The ANFIS methodology is employed to delineate the MFs and regulate the fuzzy inference system (FIS) file using back propagation algorithm. The lesser the epoch error, the more exact the training model is executed. The FIS data created by the model after learning is then used with GA to obtain optimized results (Yadav et al. 2019; Karimi et al. 2012).

To improve the ANFIS results, GA is used in this study. To put it in other way, GA is used to find the optimum ANFIS parameters as shown in ANFIS-GA flow chart in Figure 7 (Yadav et al. 2019). Here we can say that this evolutionary hybrid method has perfectly accounted for its significance in the outcomes to improve the $\mathrm{CO}_{2}$ fixation rate so as to further the result optimization of the process of $\mathrm{CO}_{2}$ capture (Vafaei et al. 2015, Moayedi et al. 2019; Yadav et al. 2019). The potentiality of this hybrid method to tune the member functions (MFs) of fuzzy inference systems and managing intricate decision-making or diagnosis systems through hybrid earning rules made this method to be triumphant. 


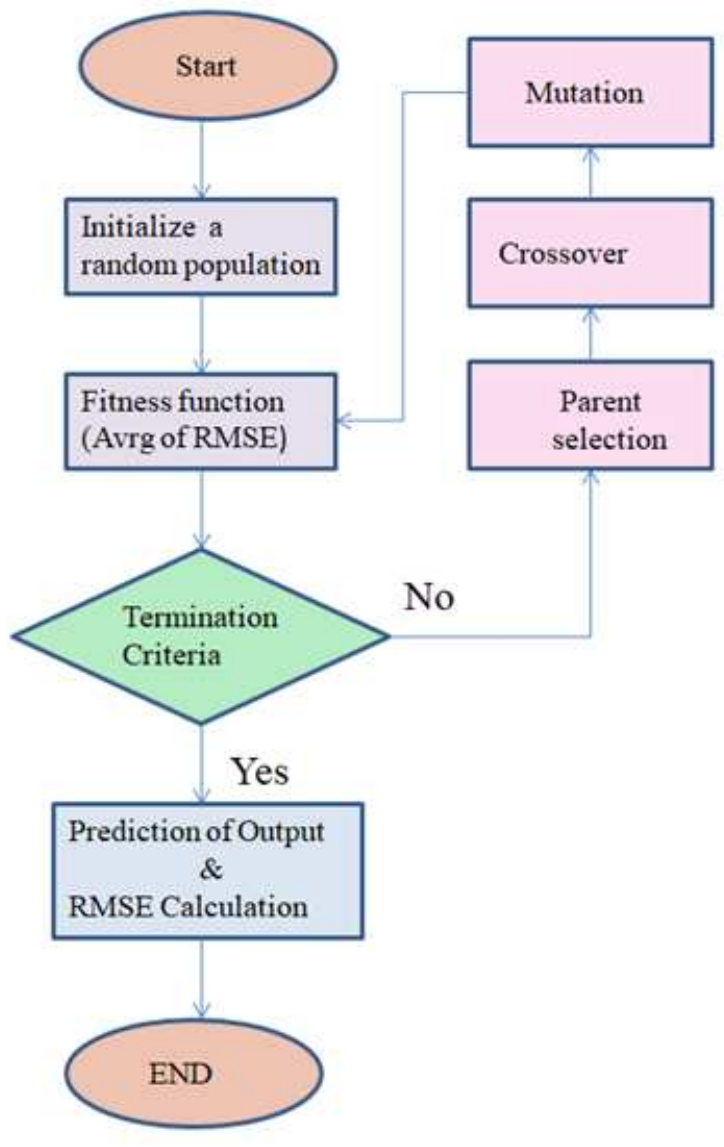

243 Fig. 7 ANFIS-GA Flow Chart

\subsection{Evaluation of Model Performances}

246 The performances of models were evaluated according to the statistical tools such as root mean

247 square error (RMSE), and coefficient of regression $\left(\mathrm{R}^{2}\right)$, Average absolute relative deviation 248 (AARD) (Wei et al. 2013). The related equations for calculation of, RMSE, AARD, $\mathrm{R}^{2}$ are given 249 in Eqs. 9,10 and 11 as follows:

$250 \quad R M S E=\sqrt{\left(\frac{1}{N}\right) \sum_{i=1}^{N}\left(X_{i}^{\text {exp }}-X_{i}^{\text {predicted }}\right)^{2}}$

$251 \quad R^{2}=1-\frac{\sum_{i=1}^{N}\left(X_{i}^{e x p}-X_{i}^{\text {predicted }}\right)^{2}}{\sum_{i=1}^{N}\left(X_{i}^{e x p}-X^{e x p}\right)^{2}}$ 
$253 \quad A A R D=\frac{100}{N} \sum_{i=1}^{N}\left|\frac{X_{i}^{\text {exp }}-X_{i}^{\text {predicted }}}{X_{i}^{\text {exp }}}\right|$

255 The $\mathrm{R}^{2}$ accepts values between 0 and 1, with values close to 1 depicting a better fit, helps assess

256 the model's performance in modeling the data set. The RMSE is used to calculate the square root 257 of variance of the prediction model's data and the actual data Which can be used to check the 258 accuracy of the developed models (Wei et al. 2013; Fazlic et al. 2015). The deviation between the 259 predicted and the experimental value was evaluated using absolute average relative deviation 260 (AARD). The model resulting in the least value of the AARD will be the best model that can be 261 used for forecasting the $\mathrm{CO}_{2}$ fixation (Kaveh et al. 2018; Fazlic et al. 2015).

\section{Results and Discussion}

\subsection{ANFIS Modeling}

265 As the principal focus of this analysis is to forecast the Micro-algae selectivity for Carbon $\left(\mathrm{CO}_{2}\right)$ 266 Capture under the operating conditions, the $\mathrm{CO}_{2}$ fixation rate was taken as the output parameter, 267 while the temperature and $\mathrm{pH}$ conditions were taken as the input parameters. It is mandatory to fix 268 the number and type of MFs, as well as the number of iterations, in order to employ the ANFIS 269 model (Lei et al. 2007; Wei et al. 2013). The input and output data ranges are critical and should 270 not be omitted while determining various operating range parameters (Lei et al 2007; Rubio et al. 271 2019).

272 The ANFIS model may be effectively trained without degrading the results by normalizing or 273 scaling (Najafi et al. 2018b). The boundary is [0 1], and variables are scaled in this boundary via 274 mapping. MineMax equation (12) is generally employed to normalize the outputs and inputs:

$275 \quad X_{n}=\frac{X^{\prime}-X_{\min }}{X_{\max }-X_{\min }}$

276 Where $X_{\max }, X_{\min }$ and $X_{n}$ are maximum, minimum and normalized data for every parameter. 
277 The data for model development was obtained from the experimental results available in the 278 literature. Determining the input parameters for learning is necessary for ANFIS, and it is among 279 the substantial challenges in the nonlinear systems modeling. The total 27 datasets are shown in 280 Table S1 (see the supporting information) split into training (20) and testing (7) to avoid over281 fitting. The Training data comparison with the ANFIS outputs is shown in Figure 8.

282

283

284

285

286

287

288

289

290

291

292

293

294

295

296
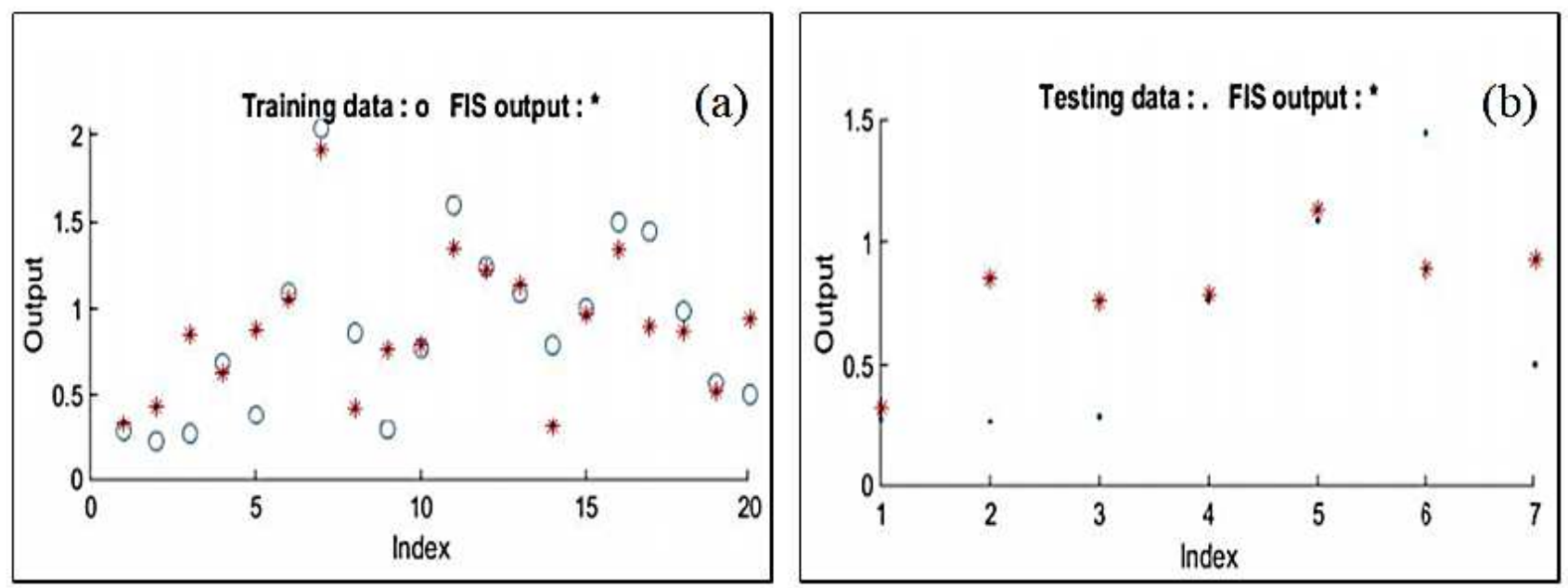

Fig. 8 (a) Training and (b) Testing Data Comparison-ANFIS

The training error (the difference between the training data and output value) calculated using root mean squared error (RMSE) at each epoch and found as 0.012962 as shown in Figure 8a. The testing data is used to check the generalization potentiality of the fuzzy inference system at each epoch and to validate the fuzzy inference model (Kurian et al. 2006). The testing error was found RMSE as 0.024753 as shown in the Figure 8b. The result obtained from the ANFIS models suggests that the best model is considered as the one which has got the lowest testing data error. At the initial part, a hybrid learning employed for predicting the parameters. The model training was set at 1000 epochs and the computational duration was less than 1 minute (Kurian et al. 2006; Ghiazi et al. 2016).

The ANFIS methodology was employed to forecast the $\mathrm{CO}_{2}$ fixation rate and to find out the relation between the input variables and output variables. Table 1 represents the ANFIS parameters. The most vital advantage of a Sugeno Fuzzy Inference System is that they capitulate 
a more accurate relationship between a larger number of outputs and inputs. Therefore, the MFs are determined via trial-and-error method.

Table 1 Details of the ANFIS for predicting the $\mathrm{CO}_{2}$ fixation rate

\begin{tabular}{|l|l|}
\hline Type & Description/Value \\
\hline Fuzzy Structure & Sugeno-type \\
\hline MF type & Triangular (trimf) \\
\hline Output MF & Constant \\
\hline $\begin{array}{l}\text { Number of fuzzy } \\
\text { Rules }\end{array}$ & 9 \\
\hline Number of Inputs & 2 \\
\hline $\begin{array}{l}\text { Number } \\
\text { Outputs }\end{array}$ & 1 \\
\hline $\begin{array}{l}\text { Training } \\
\text { Maximum epoch } \\
\text { number }\end{array}$ & 1000 \\
\hline $\begin{array}{l}\text { Computational } \\
\text { Time }\end{array}$ & Less than one min \\
\hline
\end{tabular}

302 The structure of ANFIS model-developed in this study was based on Triangular membership function for the input and Constant membership function for the Output (Husein et al. 2019). The parameters of the triangular membership function for the input variables and their ranges are shown in Table S2 and Table S3 (see the supporting information). The parameters of the constant membership function and their ranges for the output variable $\left(\mathrm{CO}_{2}\right.$ fixation rate $)$ is shown in Table

307 S4 (see the supporting information). The Number of fuzzy rules was 9 which are shown in Table 2. The values of the output membership functions for the rules are given in Table $\mathbf{S 4}$ (see the supporting information). It is very clear that the maximum $\mathrm{CO}_{2}$ fixation can be obtained for the following rules (Alarifi et al. 2019; Dasari et al. 2019). 
Table 2 Fuzzy Rule base of the optimum ANFIS structure for predicting the $\mathrm{CO}_{2}$ fixation rate

\begin{tabular}{|c|c|}
\hline S.No & Rules \\
\hline 1 & If (Temperature is Low) and ( $\mathrm{pH}$ is Low) then $\left(\mathrm{CO}_{2}\right.$ fixation_rate is out $\left.1 \mathrm{mf} 1\right)$ \\
\hline 2 & If (Temperature is Low) and ( $\mathrm{pH}$ is Medium) then $\left(\mathrm{CO}_{2}\right.$ fixation_rate is out $\left.1 \mathrm{mf} 2\right)$ \\
\hline 3 & $\begin{array}{l}\text { If (Temperature is Low) and ( } \mathrm{pH} \text { is High) then (CO2_fixation_rate is } \\
\text { out1mf3) }\end{array}$ \\
\hline 4 & If (Temperature is Medium) and ( $\mathrm{pH}$ is Low) then (CO2_fixation_rate is out $1 \mathrm{mf} 4)$ \\
\hline 5 & $\begin{array}{l}\text { If (Temperature is Medium) and ( } \mathrm{pH} \text { is Medium) then (CO2_fixation_rate is } \\
\text { out1mf5) }\end{array}$ \\
\hline 6 & If (Temperature is Medium) and ( $\mathrm{pH}$ is High) then (CO2_fixation_rate is out1mf6) \\
\hline 7 & If (Temperature is High) and ( $\mathrm{pH}$ is Low) then (CO2_fixation_rate is out1mf7) \\
\hline 8 & If (Temperature is High) and ( $\mathrm{pH}$ is Medium) then (CO2_fixation_rate is out $1 \mathrm{mf} 8)$ \\
\hline 9 & If (Temperature is High) and ( $\mathrm{pH}$ is High) then (CO2_fixation_rate is out $1 \mathrm{mf} 9)$ \\
\hline
\end{tabular}

- If (Temperature is Low) and (pH is High) then $\left(\mathrm{CO}_{2} \_\right.$fixation_rate is 2.28708)

- If (Temperature is High) and ( $\mathrm{pH}$ is Medium) then $\left(\mathrm{CO}_{2} \_\right.$fixation_rate is 2.86869) 
325 algae decreases at elevated temperatures. It is very clear from the results that low or medium

326 temperature conditions and high $\mathrm{pH}$ conditions are highly suitable for maximum $\mathrm{CO}_{2}$ fixation 327 rates. The above results can be used by the industries for scaling up the Carbon-capture process 328 using Micro-algal species (Eseye et al. 2017; Xu et al. 2011).

329
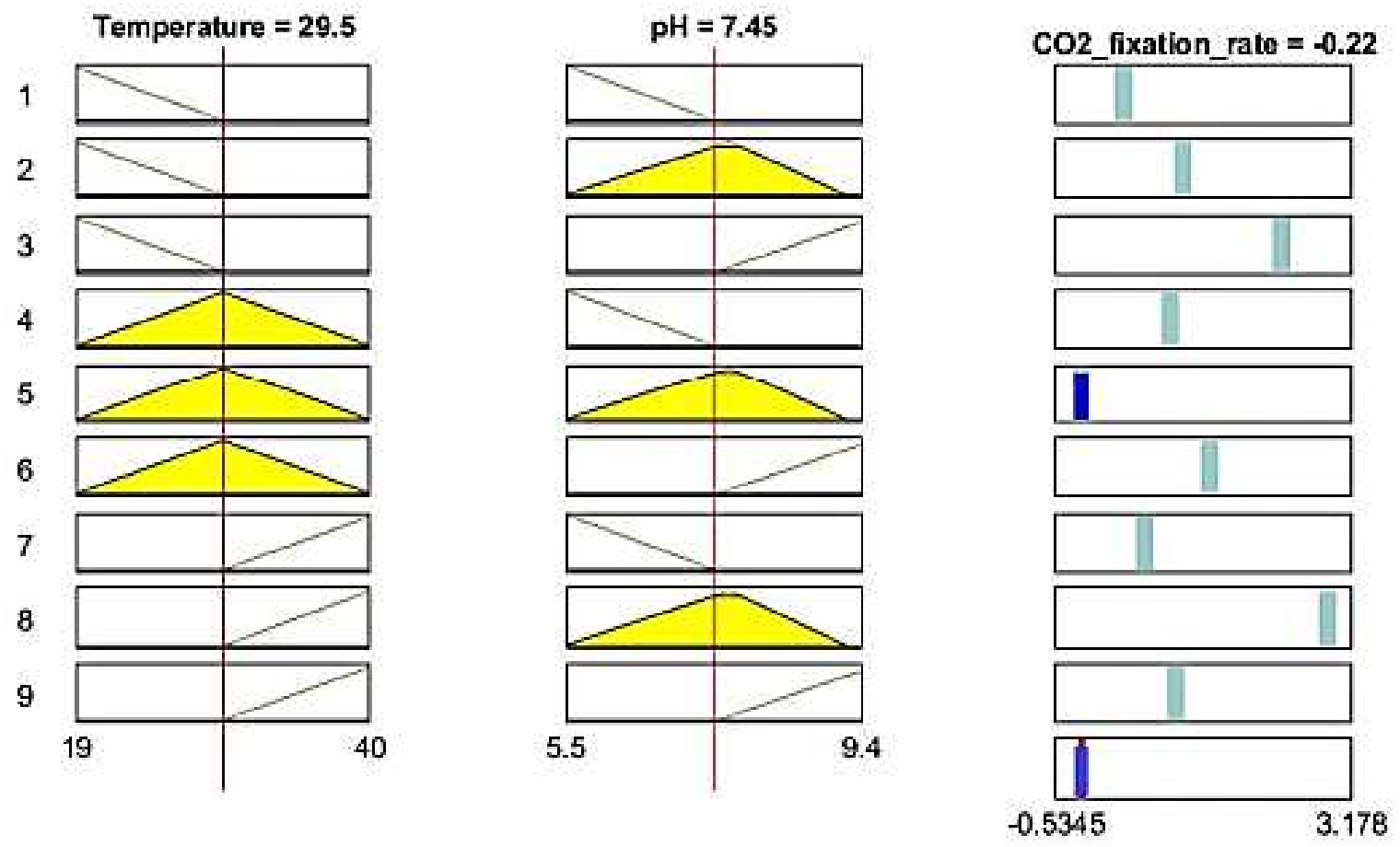

331 Fig. 9 Rules used in ANFIS for the input parameters temperature and $\mathrm{pH}$, and the output 332 parameter $\mathrm{CO}_{2}$ fixation rate. 


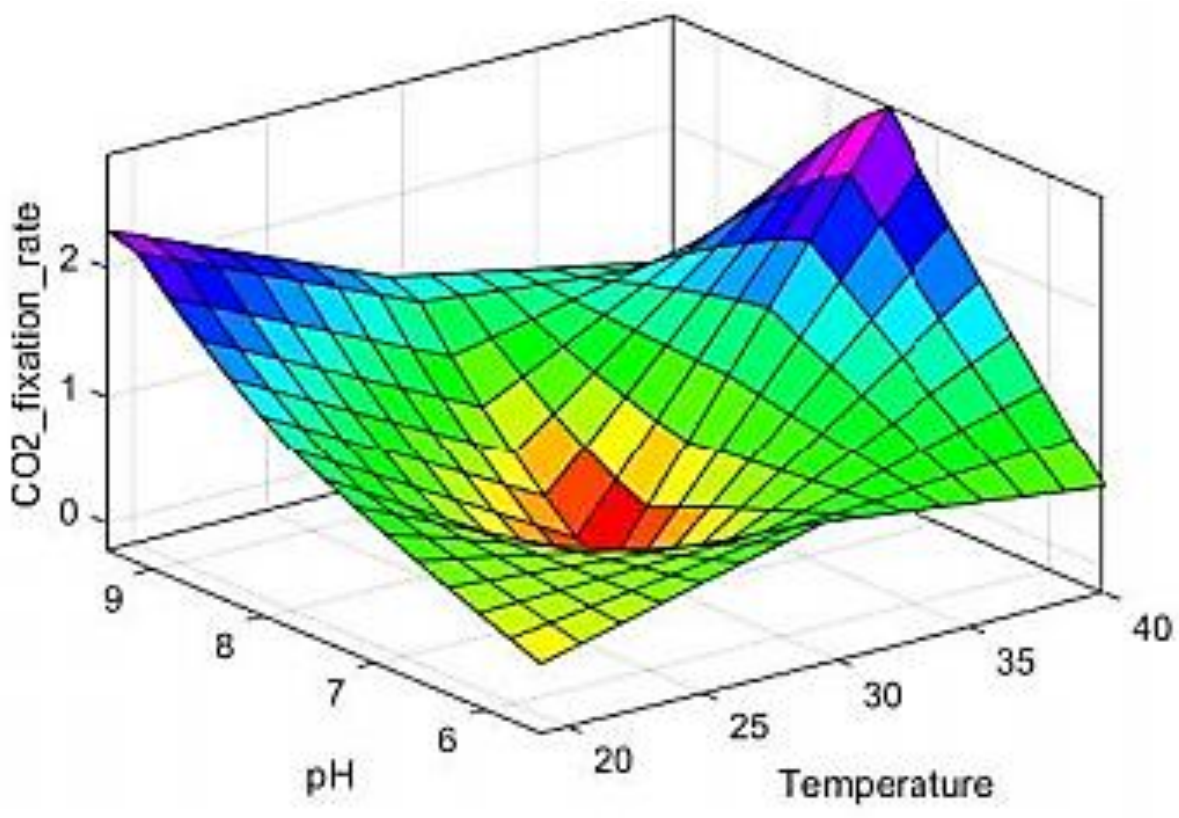

Fig. 10 Surface plot of the $\mathrm{CO}_{2}$ fixation rate with respect to $\mathrm{pH}$ and temperature

\subsection{Configuring GA-ANFIS model for $\mathrm{CO}_{2}$ Fixation rate optimization}

In this study, using the programming language of MATLAB R2020a, GA-ANFIS hybrid approach was propounded for $\mathrm{CO}_{2}$ fixation rate prediction. As the first step, the parameters (Temperature and $\mathrm{pH}$ ) were set as input factors, and $\mathrm{CO}_{2}$ fixation rate was set as output factor for the ANFIS Models. The results from ANFIS shows that Training and Testing datasets have an $\mathrm{R}^{2}$ value of 0.92345 and 0.91724 respectively as shown in Table 3.

342 In order to increase the prediction potentiality of the ANFIS model, hybrid models were formed 343 by using GA algorithm to optimize the ANFIS parameters. In GA-ANFIS, GA and ANFIS are 344 integrated to enlarge its prediction efficiency. GA-ANFIS method was also configured by coding in MATLAB 2020a to forecast the $\mathrm{CO}_{2}$ fixation rate of various micro-algal species. The average 346 of the Root mean square error (RMSE) of the training and testing datasets was considered as the 347 fitness function for the Genetic Algorithm (Shahlaei et al. 2012). GA is accomplished to ameliorate 348 ANFIS performance and lessen the error percentage by tuning and optimizing the membership 349 functions of a Sugeno type fuzzy inference system (Yadav et al. 2019; Karimi et al. 2012). 
Table 3 Stastical indexes for the prediction model of $\mathrm{CO}_{2}$ fixation rate (ANFIS/GA-ANFIS)

\begin{tabular}{|l|l|l|l|l|}
\hline & \multicolumn{2}{|l|}{ ANFIS } & GA-ANFIS \\
\hline & Training dataset & $\begin{array}{l}\text { Testing } \\
\text { dataset }\end{array}$ & Training dataset & Testing dataset \\
\hline RMSE & 0.012962 & 0.024753 & 0.000431 & 0.00056 \\
\hline$R^{2}$ & $0 . .92345$ & 0.91724 & 0.97865 & 0.98457 \\
\hline AARD & 0.083262 & 0.064512 & 0.044354 & 0.032156 \\
\hline
\end{tabular}

Global Optimization tool box in MATLAB R2020a were used for generating the evolution of the best and average fitness over 150 generations using 'ga' function. The pertinent GA parameters used in the optimization system are given in Table 4. The number of individuals in each iteration or population is 100 and maximum number of generations is 150 (based on trial-and-error method) 356 (Shahlaei et al. 2012). In the present study, the Population Size is set to 100. By enlarging the 357 population size, the genetic algorithm is able to discover more points and produce a better outcome. 358 (Momeni et al. 2014; Armaghani et al. 2019).

Table 4 GA Parameters

\begin{tabular}{|l|l|}
\hline Parameter & Value \\
\hline Maximum Iterations Number & 300 \\
\hline Population size & 100 \\
\hline No of generations & 150 \\
\hline Parent selection & Stochastic uniform \\
\hline Elite count & 3 \\
\hline Crossover fraction & 0.9 \\
\hline Mutation function & Adaptive feasible \\
\hline
\end{tabular}


Crossover Fraction is defined as the fraction of individuals in the upcoming generation, excluding the elite children, that are generated by crossover (rest of them are generated by mutation). A crossover fraction of ' 1 ' delineates that all children except the elite individuals are crossover children. (Saraswat et al. 2013). A crossover fraction of ' 0 ' delineates that all children are mutation children. (Shahlaei et al. 2012). A crossover rate of $90 \%$ is used and the crossover operator is executed using scattered crossover function. Scattered crossover function generates an arbitrary binary vector that amalgamates the genes to produce new chromosome (Karimi et al. 2012). An adaptive mutation function has been employed that arbitrarily generates directions that are adaptive with respect to the last triumphant or unsuccessful generation. The mutation determines the direction and step length that assuage bounds and linear constraints (Shahlaei et al. 2012; Kaveh et al. 2018). In the present study the elite count is 3 which signifies the number of individuals with the best fitness values in the present generation that are guaranteed to survive to the next generation. These individuals are better known as the elite children (Badhwar et al. 2020; Kumar et al. 2019).

The performance of a GA is affected by the diversity of the initial population as shown in Figure 11a and Figure 11b. If the average distance between the individuals is large, it is indication of high diversity, if the average distance is small its represent low diversity in the population. If the diversity is too high or too low, the genetic algorithm might not perform well (Momeni et al. 2014; Armaghani et al. 2019). The best fitness plot for the GA maps the convergence of the best fitness values of successive generations towards the final optimum value as shown in Figure 11c. In the present study, the population size is set to 100 (Badhwar et al. 2020; Kumar et al. 2019). Increasing the population size permits the genetic algorithm to explore more points and as a way to obtain a better result (Momeni et al. 2014; Armaghani et al. 2019). Some of the eminent selection methods used includes uniform, roulette wheel and tournament. The selection method used in the present study is stochastic uniform an individual can be chosen as a parent several times; in which case it gives its genes to multiple children. 

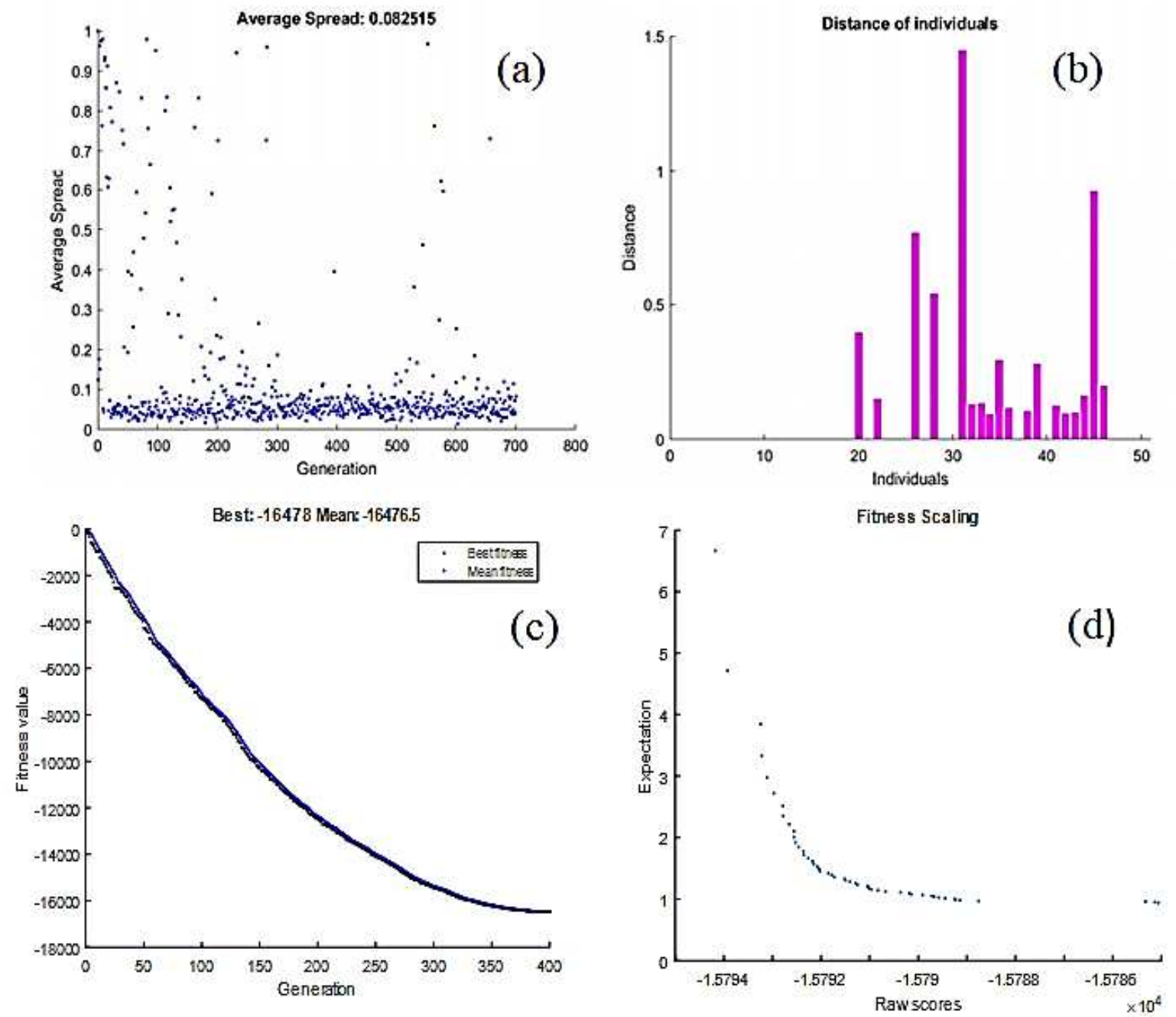

390 Fig. 11 (a) Average spread of the Individuals with respect to the Generations using Genetic 391 Algorithm (b) verage distance between the Individuals using Genetic Algorithm (c) Representative 392 plots generated from the optimization by GA using MATLAB R2020a: Best and average fitness 393 values with successive generations showed good convergence to the optimum value (d) Fitness scaling of the raw scores

396 Eventually, another parameter that influences the diversity of the population is the fitness scaling 397 as shown in Figure 11d. Before the GA's selection phase, the fitness scaling modulates the fitness 398 values (scaled values). This is accomplished without altering the ranking order, thus the fittest 399 individual based on raw fitness value is still the best in the scaled rank. The only thing that changes 
are the values, and hence the likelihood of an individual being chosen for mating via the selection method (Saraswat et al. 2013). If the fitness values differ too extensively, the individuals with the least values replicate instantly, taking over the population gene pool too swiftly and preventing the GA from searching other areas of the solution space (Badhwar et al. 2020; Armaghani et al. 2019). Contrarily, if the values differ only a bit, all individuals have almost the same possibility of reproduction and this process will advance very deliberately. Table 3 indicates the $\mathrm{R}^{2}$, RMSE and AARD values for the given ANFIS and GA-ANFIS models. The results clearly show that GAANFIS have better performance compared to ANFIS models as shown in Table 3 and Figure S1 and Figure S2 (see the supporting information) (Kumar et al. 2019; Badhwar et al. 2020).

\section{Conclusions}

The higher $\mathrm{CO}_{2}$ fixation rate of micro-algae is of great significance in determining the potential of biomass and its possible application areas for industrial purpose. In this study, the effect of two input-parameters on $\mathrm{CO}_{2}$ fixation rate have been investigated with artificial intelligence tools such as, ANFIS, GA-ANFIS models. The prime findings have been summarized as-

A dataset consisting of 27 data pairs $\left(\mathrm{CO}_{2}\right.$ fixation rate) collected from various sources were employed to examine the authenticity of the ANFIS and GA-ANFIS models and to study their behavior for training a small number of datasets. Firstly, ANFIS models were developed for predicting the $\mathrm{CO}_{2}$ fixation rate for the given micro-algae with Temperature and $\mathrm{pH}$ as the input parameters. The Gaussian membership function was used for the input and constant membership function was used for the output respectively. The hybrid GA-ANFIS models improved the prediction efficiency of the ANFIS model to avoid local minima and achieve global convergence rapidly with a great precision. The statistical parameters demonstrated that the GA-ANFIS model has the best predicting performance compared to ANFIS and have better prediction results for small datasets. The developed models in the present study may be of great importance to the researchers in order to increase the $\mathrm{CO}_{2}$ fixation rate for industrial scale-up. 
427 Supplementary Information The online version contains supplementary material available at

428 Acknowledgments The authors acknowledge respective affiliated institutes and departments for providing the

429 facilities to carry out this work. OSK acknowledges Professor Rajnish Kumar, ChE-IIT Madras for encouragement 430 and support to complete the work.

431 Authorship contribution statement HP: data collection and validation, method validation, writing draft. KK:

432 formal analysis, review OSK: conceptualization, methodology, project management, visualization, , investigation, 433 supervision, writing.

434 Funding The authors acknowledge DST-SERB government of India for funding in the form of fellowship

435 which was used partially. There was no direct funding available for this work however, partial funding for this work 436 was used from the project PDF/2017/003075 granted by DST-SERB-India.

437 Data availability The data generated or analyzed during this study is included in this published article and its 438 supplementary information files.

\section{Compliance with ethical standards}

440 Ethics approval and consent to participate Not applicable for this section.

441 Consent for publication Not applicable for this section.

442 Conflict of interest The authors declare that they have no competing interests. 
443

444

445

446

447

448

449

450

451

452

453

454

455

456

457

458

459

460

461

462

463

464

465

466

467

468

469

470

\section{References}

Aiyer, S., Prasad, R., Kumar, M., Nirvikar, K., Jain, B., \& Kushwaha, O. S. (2016). Fluorescent carbon nanodots for targeted in vitro cancer cell imaging. Applied Materials Today, 4, 71-77. https://doi.org/10.1016/j.apmt.2016.07.001

Alarifi, Ibrahim M., Hoang M. Nguyen, Ali Naderi Bakhtiyari, \& Amin Asadi (2019). Feasibility of ANFIS-PSO and ANFIS-GA models in predicting thermophysical properties of $\mathrm{Al}_{2} \mathrm{O}_{3}-\mathrm{MWCNT} /$ oil hybrid nanofluid. Materials 12, 21, 3628. https://doi.org/10.3390/ma12213628

Appiah, M., Li, F., \& Korankye, B. (2021). Modeling the linkages among $\mathrm{CO}_{2}$ emission, energy consumption, and industrialization in sub-Saharan African (SSA) countries. Environmental Science and Pollution Research, 1-16. https://doi.org/10.1007/s11356-021-12412-z

Armaghani, Danial Jahed, Mahdi Hasanipanah, Amir Mahdiyar, Muhd Zaimi Abd Majid, Hassan Bakhshandeh Amnieh, \& Mahmood MD Tahir (2018). Airblast prediction through a hybrid genetic algorithm-ANN model. Neural Computing and Applications 29, 9, 619-629. https://doi.org/10.1007/s00521-016-2598-8

Badhwar, P., Kumar, A., Yadav, A., Kumar, P., Siwach, R., Chhabra, D., \& Dubey, K. K. (2020). Improved pullulan production and process optimization using novel GA-ANN and GA-ANFIS hybrid statistical tools. Biomolecules, 10(1), 124. https://doi.org/10.3390/biom10010124

Barbir, F. (2012). PEM fuel cells: theory and practice. Academic press.

Begic Fazlic, Lejla, Korana Avdagic, and Samir Omanovic (2015). GA-ANFIS expert system prototype for prediction of dermatological diseases. Digital Healthcare Empowering Europeans, pp. 622-626. IOS Press. https://doi.org/10.3233/978-1-61499-512-8-622

Boot-Handford, M.E., Abanades, J.C., Anthony, E.J., Blunt, M.J., Brandani, S., Mac Dowell, N., Fernández, J.R., Ferrari, M.C., Gross, R., Hallett, J.P. \& Haszeldine, R.S., (2014). Carbon capture and storage update. Energy \& Environmental Science, 7(1), 130-189. https://doi.org/10.1039/C3EE42350F

Brabec, C. J., Sariciftci, N. S., \& Hummelen, J. C. (2001). Plastic solar cells. Advanced functional materials, 11(1), 15-26. https://doi.org/10.1002/1616-3028(200102)11:1\%3C15::AID-ADFM15\%3E3.0.CO;2-A

Buragohain, M., \& Mahanta, C. (2008). A novel approach for ANFIS modelling based on full factorial design. Applied soft computing, 8(1), 609-625. https://doi.org/10.1016/j.asoc.2007.03.010 
471 Burton, T., Jenkins, N., Sharpe, D., \& Bossanyi, E. (2011). Wind energy handbook. John Wiley \& Sons.

$472 \quad$ https://doi.org/10.1002/9781119992714

473 Chiu, S.Y., Kao, C.Y., Huang, T.T., Lin, C.J., Ong, S.C. Chen, C.D. (2011). Microalgal Biomass 474 Production and On-site Bioremediation of Carbon Dioxide, Nitrogen Oxide and Sulfur Dioxide from Flue 475 Gas Using Chlorella sp. Cultures. Bioresour. Technol. 102, 9135-9142. 476 https://doi.org/10.1016/j.biortech.2011.06.091

477 Dasari, Murali, A. Sreenivasula Reddy, and M. Vijaya Kumar (2019). "GA-ANFIS PID compensated 478 model reference adaptive control for BLDC motor." International Journal of Power Electronics and Drive 479 Systems 10, 1, 265. http://doi.org/10.11591/ijpeds.v10.i1.pp265-276

480 de Morais, M.G. and Costa, J.A.V. (2007b). Carbon Dioxide Fixation by Chlorella kessleri, C. vulgaris, 481 Scenedesmus obliquus and Spirulina sp. Cultivated in Flasks and Vertical Tubular Photobioreactors. 482 Biotechnol. Lett. 29, 1349-1352. https://doi.org/10.1007/s10529-007-9394-6

483 De Vries, J. (1994). The industrial revolution and the industrious revolution. The Journal of Economic 484 History, 54(2), 249-270.

485 Dods, M. N., Kim, E. J., Long, J. R., \& Weston, S. C. (2021). Deep CCS: Moving Beyond 90 \% Carbon 486 Dioxide Capture. Environmental Science \& Technology. https://doi.org/10.1021/acs.est.0c07390

487 Eseye, A. T., Zhang, J., Zheng, D., Li, H., \& Jingfu, G. (2017). Short-term wind power forecasting using a 488 double-stage hierarchical hybrid GA-ANFIS approach. IEEE 2nd international conference on cloud 489 computing and big data analysis (ICCCBDA) (pp. 499-503). IEEE.

490 491 492 493 494 495 496 497 498 499

Ghiasi, Mohammad M., Milad Arabloo, Amir H. Mohammadi, and Tohid Barghi (2016). Application of ANFIS soft computing technique in modeling the $\mathrm{CO}_{2}$ capture with MEA, DEA, and TEA aqueous solutions. International Journal of Greenhouse Gas Control 49, 47-54. https://doi.org/10.1016/j.ijggc.2016.02.015

Ghosh, A., \& Kiran, B. (2017). Carbon concentration in algae: reducing $\mathrm{CO}_{2}$ from exhaust gas. Trends in biotechnology, 35(9), 806-808. https://doi.org/10.1016/j.tibtech.2017.05.003

Gibbins, J., \& Chalmers, H. (2008). Carbon capture and storage. Energy policy, 36(12), 4317-4322. https://doi.org/10.1016/j.enpol.2008.09.058

Gomez-Villa, H., Voltolina, D., Nieves, M. and Pina, P. (2005). Biomass Production and Nutrient Budget in Outdoor Cultures of Scenedesmus obliquus (Chlorophyceae) in Artificial Wastewater, under the Winter 
and Summer Conditions of Mazatlan, Sinaloa, Mexico. Vie Milieu. 55, 121-126. https://hal.sorbonneuniversite.fr/hal-03219036

Houck, Christopher R., Jeff Joines, and Michael G. Kay (1995). A genetic algorithm for function optimization: a Matlab implementation. Ncsu-ie tr 95, 9, 1-10.

Huntley, M.E. and Redalje, D.J. (2007). $\mathrm{CO}_{2}$ Mitigation and Renewable Oil from Photsynthetic Microbes: A New Appraisal. Mitig. Adapt. Strateg. Glob. Change 12, 573-608. https://doi.org/10.1007/s11027-006$\underline{7304-1}$

Husein, A. M., Simarmata, A. M., Harahap, M., Aisyah, S., \& Dharma, A. (2019). Implementation ANFIS Method for Prediction Needs Drug-based Population Diseases and Patient. International Conference of Computer Science and Information Technology (ICoSNIKOM) (pp. 1-5). IEEE. https://doi.org/10.1109/ICoSNIKOM48755.2019.9111485

Jacob-Lopes, E., Revah, S., Hernández, S., Shirai, K. and Franco, T.T. (2009). Development of Operational Strategies to Remove Carbon Dioxide in Photobioreactors. Chem. Eng. J. 153, 120-126. https://doi.org/10.1016/j.cej.2009.06.025

Jang, J. S. (1993). ANFIS: adaptive-network-based fuzzy inference system. IEEE transactions on systems, man, and cybernetics, 23(3), 665-685. https://doi.org/10.1109/21.256541

Jiang, H. M., Kwong, C. K., Ip, W. H., \& Wong, T. C. (2012). Modeling customer satisfaction for new product development using a PSO-based ANFIS approach. Applied Soft Computing, 12(2), 726-734. https://doi.org/10.1016/j.asoc.2011.10.020

Jonker, J. G. G., \& Faaij, A. P. C. (2013). Techno-economic assessment of micro-algae as feedstock for renewable bio-energy production. Applied $\quad$ Energy, 102, 461-475. https://doi.org/10.1016/j.apenergy.2012.07.053

Kahia, M., \& Jebli, M. B. (2021). Industrial growth, clean energy generation, and pollution: evidence from top ten industrial countries. Environmental Science and Pollution Research, 1-10. https://doi.org/10.1007/s11356-021-15311-5

25 Karimi, Hajir, and Fakheri Yousefi (2012). Application of artificial neural network-genetic algorithm (ANN-GA) to correlation of density in nanofluids. Fluid Phase Equilibria 336, 79-83. https://doi.org/10.1016/j.fluid.2012.08.019 

models in prediction of peak ground acceleration. Iran University of Science \& Technology, 8(1), 1-14.

Khashei-Siuki, Abbas, and Mahbobeh Sarbazi (2015). Evaluation of ANFIS, ANN, and geostatistical models to spatial distribution of groundwater quality (case study: Mashhad plain in Iran). Arabian Journal of Geosciences 8, 2, 903-912. https://doi.org/10.1007/s12517-013-1179-8

533 Kumar, V., Kumar, A., Chhabra, D., \& Shukla, P. (2019). Improved biobleaching of mixed hardwood pulp 534 and process optimization using novel GA-ANN and GA-ANFIS hybrid statistical tools. Bioresource technology, 271, 274-282. https://doi.org/10.1016/j.biortech.2018.09.115

536 Kurian, Ciji Pearl, V. I. George, Jayadev Bhat, and Radhakrishna S. Aithal (2006). ANFIS model for the 537 time series prediction of interior daylight illuminance. International Journal on Artificial Intelligence and 538 Machine Learning 6, 3, 35-40.

539 Kushwaha, O. S., Avadhani, C. V., \& Singh, R. P. (2013). Photo-oxidative degradation of 540 polybenzimidazole derivative membrane. Advanced Materials Letters, 4(10), 762-768. $541 \quad$ http://dx.doi.org/10.5185/amlett.2013.3432

542 Kushwaha, O. S., Avadhani, C. V., \& Singh, R. P. (2014). Effect of UV rays on degradation and stability 543 of high performance polymer membranes. Advanced Materials Letters, 5(5), 272-279. 544 https://dx.doi.org/10.5185/amlett.2014.10533

545 Kushwaha, O. S., Avadhani, C. V., \& Singh, R. P. (2015). Preparation and characterization of self546 photostabilizing UV-durable bionanocomposite membranes for outdoor applications. Carbohydrate 547 polymers, 123, 164-173. https://doi.org/10.1016/j.carbpol.2014.12.062

548 Lei, X. (2021). Fault Diagnosis for Vehicle on-Board Equipment's of High-Speed Railway Based on GA549 ANFIS Model. Proceedings of the 7th International Symposium on Innovation \& Sustainability of Modern 550 Railway (Vol. 14, p. 208). IOS Press.

551 Lei, Y., He, Z., Zi, Y., \& Hu, Q. (2007). Fault diagnosis of rotating machinery based on multiple ANFIS 552 combination with GAs. Mechanical systems and signal processing, 21 (5), 2280-2294. 553 https://doi.org/10.1016/j.ymssp.2006.11.003

554 Maulik, Ujjwal, and Sanghamitra Bandyopadhyay (2000). Genetic algorithm-based clustering 555 technique. Pattern recognition, 33, 9, 1455-1465. https://doi.org/10.1016/S0031-3203(99)00137-5 
557 Fluorescent carbon dots driven from ayurvedic medicinal plants for cancer cell imaging and phototherapy.

558 Heliyon, 5(9), e02483. https://doi.org/10.1016/j.heliyon.2019.e02483

559 Mellit, A., \& Kalogirou, S. A. (2011). ANFIS-based modelling for photovoltaic power supply system: A case study. Renewable energy, 36(1), 250-258. https://doi.org/10.1016/j.renene.2010.06.028

561 Moayedi, H., Mehrabi, M., Kalantar, B., Abdullahi Mu’azu, M., A. Rashid, A. S., Foong, L. K., \& Nguyen,

562 H. (2019). Novel hybrids of adaptive neuro-fuzzy inference system (ANFIS) with several metaheuristic

563 algorithms for spatial susceptibility assessment of seismic-induced landslide. Geomatics, Natural Hazards

564 and Risk, 10(1), 1879-1911. https://doi.org/10.1080/19475705.2019.1650126

565 Momeni, E., R. Nazir, D. Jahed Armaghani, and H. Maizir (2014). Prediction of pile bearing capacity using 566 a hybrid genetic algorithm-based ANN. Measurement, $122-131$.

567 https://doi.org/10.1016/j.measurement.2014.08.007

568 Moniz, E. J. (2010). Nanotechnology for the energy challenge. John Wiley \& Sons.

569 Murakami, M. and Ikenouchi, M. (1997). The Biological $\mathrm{CO}_{2}$ Fixation and Utilization Project by RITE (2):

570 Screening and Breeding of Microalgae with High Capability in Fixing $\mathrm{CO}_{2}$. Energy Convers. Manage. 38 :

571 S493-S497. https://doi.org/10.1016/S0196-8904(96)00316-0

572 Najafi, Bahman, and Sina Faizollahzadeh Ardabili (2018). Application of ANFIS, ANN, and logistic 573 methods in estimating biogas production from spent mushroom compost (SMC). Resources, Conservation 574 and Recycling 133, 169-178. https://doi.org/10.1016/j.resconrec.2018.02.025

575 Najafi, Bahman, Sina Faizollahzadeh Ardabili, Shahaboddin Shamshirband, Kwok-wing Chau, and Timon

576 Rabczuk (2018). Application of ANNs, ANFIS and RSM to estimating and optimizing the parameters that 577 affect the yield and cost of biodiesel production. Engineering Applications of Computational Fluid 578 Mechanics 12, 1, 611-624. https://doi.org/10.1080/19942060.2018.1502688

579 Panwar, N. L., Kaushik, S. C., \& Kothari, S. (2011). Role of renewable energy sources in environmental 580 protection: A review. Renewable and sustainable energy reviews, 15(3), 1513-1524. 581 https://doi.org/10.1016/j.rser.2010.11.037

582 Rezaeianzadeh, Mehdi, Hossein Tabari, A. Arabi Yazdi, S. Isik, \& L. Kalin (2014). Flood flow forecasting 583 using ANN, ANFIS and regression models. Neural Computing and Applications 25, 1, 25-37. 584 https://doi.org/10.1007/s00521-013-1443-6 
Rezakazemi, M., Dashti, A., Asghari, M., \& Shirazian, S. (2017). H2-selective mixed matrix membranes modeling using ANFIS, PSO-ANFIS, GA-ANFIS. International Journal of Hydrogen Energy, 42(22), 15211-15225. https://doi.org/10.1016/j.ijhydene.2017.04.044

Rubio, J. D. J., Cruz, D. R., Elias, I., Ochoa, G., Balcazar, R., \& Aguilar, A. (2019). ANFIS system for classification of brain signals. Journal of Intelligent \& Fuzzy Systems, 37(3), 4033-4041. https://doi.org/10.3390/app10124239

Sakai, N., Sakamoto, Y., Kishimoto, N., Chihara, M. \& Karube, I. (1995). Chlorella Strains from Hot Springs Tolerant to High Temperature and High $\mathrm{CO}_{2}$. Energy Convers. Manage. 36, 693-696. https://doi.org/10.1016/0196-8904(95)00100-R

Saraswat, M., \& Sharma, A. K. (2013). Genetic Algorithm for optimization using MATLAB. International Journal of Advanced Research in Computer Science, 4(3), 155-159.

Sarkheyli, Arezoo, Azlan Mohd Zain, \& Safian Sharif (2015). Robust optimization of ANFIS based on a new modified GA. Neurocomputing 166, 357-366. https://doi.org/10.1016/j.neucom.2015.03.060

Sayre, R. (2010). Microalgae: the potential for carbon capture. Bioscience, 60(9), 722-727. https://doi.org/10.1525/bio.2010.60.9.9

Scragg, A.H., Illman, A.M., Carden, A. \& Shales, S.W. (2002). Growth of Microalgae with Increased Calorific Values in a Tubular Bioreactor. Biomass Bioenergy, 23, 67-73. https://doi.org/10.1016/S09619534(02)00028-4

Shahlaei, Mohsen, Armin Madadkar-Sobhani, Lotfollah Saghaie, \& Afshin Fassihi (2012). Application of an expert system based on Genetic Algorithm-Adaptive Neuro-Fuzzy Inference System (GA-ANFIS) in QSAR of cathepsin K inhibitors. Expert Systems with Applications 39, 6 6182-6191. https://doi.org/10.1016/j.eswa.2011.11.106

Singh, R. P., \& Kushwaha, O. S. (2013). Polymer solar cells: an overview. Macromolecular Symposia, 327, 1, 128-149). https://doi.org/10.1002/masy.201350516

Singh, Rajesh, Ashutosh Kainthola, \& T. N. Singh (2012). Estimation of elastic constant of rocks using an ANFIS approach. Applied Soft Computing 12, 1, 40-45.

Stephenson, A.L., Dennis, J.S., Howe, C.J., Scott, S.A. \& Smith, A.G. (2010). Influence of Nitrogenlimitation Regime on the Production by Chlorella vulgaris of Lipids for Biodiesel Feedstocks. Biofuels 1, 47-58. https://doi.org/10.4155/bfs.09.1 
614 Vafaei, S., Rezvani, A., Gandomkar, M., \& Izadbakhsh, M. (2015). Enhancement of grid-connected 615 photovoltaic system using ANFIS-GA under different circumstances. Frontiers in Energy, 9(3), 322-334.

616 https://doi.org/10.1007/s11708-015-0362-x

617 Wei, Liang-Ying (2013). A hybrid model based on ANFIS and adaptive expectation genetic algorithm to 618 forecast TAIEX. Economic Modelling, 33, 893-899. https://doi.org/10.1016/j.econmod.2013.06.009

619 Xu, A. D., Fan, Y. H., \& Li, Z. Q. (2011). Modeling of switched reluctance motor based on GA620 ANFIS. Electric Machines and Control, 15(7), 54-59.

621 Xu, Z., Liu, L., \& Wu, L. (2021). Forecasting the carbon dioxide emissions in 53 countries and regions 622 using a non-equigap grey model. Environmental Science and Pollution Research, 28(13), 15659-15672. 623 https://doi.org/10.1007/s11356-020-11638-7

624 Yadav, Harendra Kumar, Yash Pal, \& Madan Mohan Tripathi (2019). A novel GA-ANFIS hybrid model 625 for short-term solar PV power forecasting in Indian electricity market. Journal of Information and 626 Optimization Sciences 40, 2, 377-395. https://doi.org/10.1080/02522667.2019.1580880

627 Yang, Haiqing, Mahdi Hasanipanah, M. M. Tahir, and Dieu Tien Bui (2020). Intelligent prediction of 628 blasting-induced ground vibration using ANFIS optimized by GA and PSO. Natural Resources 629 Research, 29, 2, 739-750. https://doi.org/10.1007/s11053-019-09515-3

630 Yaseen, Z. M., Ebtehaj, I., Bonakdari, H., Deo, R. C., Mehr, A. D., Mohtar, W. H. M. W., ... \& Singh, V. 631 P. (2017). Novel approach for streamflow forecasting using a hybrid ANFIS-FFA model. Journal of 632 Hydrology, 554, 263-276. https://doi.org/10.1016/j.jhydrol.2017.09.007

633 Yilmaz, Işık, and Oguz Kaynar (2011). Multiple regression, ANN (RBF, MLP) and ANFIS models for 634 prediction of swell potential of clayey soils. Expert systems with applications 38, 5, 5958-5966. 635 https://doi.org/10.1016/j.eswa.2010.11.027

636 Yun, Y.S., Lee, S.B., Park, J.M., Lee, C.I. and Yang, J.W. (1997). Carbon Dioxide Fixation by Algae 637 Cultivation Using Wastewater Nutrient. J. Chem. Technol. Biotechnol. 69, 451-455. 638 https://doi.org/10.1002/(SICI)1097-4660(199708)69:4\%3C451::AID-JCTB733\%3E3.0.CO;2-M

639 Zhou, Jian, Chuanqi Li, Chelang A. Arslan, Mahdi Hasanipanah, and Hassan Bakhshandeh Amnieh (2019).

640 Performance evaluation of hybrid FFA-ANFIS and GA-ANFIS models to predict particle size distribution 641 of a muck-pile after blasting. Engineering with computers 1-10. https://doi.org/10.1007/s00366-019$642 \underline{00822-0}$ 


\section{Supplementary Files}

This is a list of supplementary files associated with this preprint. Click to download.

- Supplementarylnformation1.docx 